\begin{tabular}{cc|c}
\hline Tar. Bil. Der. & Tarm Bilimleri Dergisi & Journal of Agricultural Sciences \\
& $\begin{array}{c}\text { Dergi web sayfası: } \\
\text { www.agri.ankara.edu.tr/dergi }\end{array}$ & Journal homepage: \\
& www.agri.ankara.edu.tr/journal
\end{tabular}

\title{
Design of a Nozzle-Height Control System Using a Permanent Magnet Tubular Linear Synchronous Motor
}

\author{
Ahmet ILICA ${ }^{\mathrm{a}}$, Ali Fuat $\mathrm{BOZ}^{\mathrm{b}}$ \\ ${ }^{a}$ Sakarya University, Institute of Natural Sciences, Department of Electronics and Computer Education, Serdivan, Sakarya, TURKEY \\ ${ }^{\boldsymbol{b}}$ Sakarya University, Faculty of Technology, Department of Electrical and Electronics Engineering, Serdivan, Sakarya, TURKEY
}

\section{ARTICLE INFO}

Research Article

DOI: $10.15832 /$ ankutbd.456662

Corresponding Author: Ahmet ILICA, E-mail: ahmet.ilica@ogr.sakarya.edu.tr, Tel: +90 (506) 3375418

Received: 17 January 2017, Received in Revised Form: 18 September 2017, Accepted: 19 September 2017

\begin{abstract}
In agricultural spraying, keeping the spray at the correct height reduces pesticide drift and provides uniformly distributed pesticide accumulation on the target plant. In this study, an agricultural nozzle-height control test system was developed using a permanent magnet tubular linear synchronous motor (PMTLSM) that can adjust the height between the spraying nozzle and the plant. The developed system was experimentally tested in the laboratory environment and under field conditions. According to the experimental results, the nozzle height coefficient of variation $(\mathrm{CV})$ value decreased from $16.77 \%$ to $5.17 \%$, while the uniformity of distribution in the forward direction increased from $56.57 \%$ to $86.11 \%$ at 12 $\mathrm{km} \mathrm{h}^{-1}$ under field conditions. Under test conditions it was found that the developed system keeps the distance between differently sized plants and the nozzle at the set point with minimum error.
\end{abstract}

Keywords: Agricultural spraying; Nozzle height control; Permanent magnet tubular linear synchronous motor

(C) Ankara Üniversitesi Ziraat Fakültesi

\section{Introduction}

The rapid increase in the world population, highquality food demand and the expectation of maximum yield from accessible agricultural land leads to more intensive farming practices (Matthews 2008). Agricultural diseases and pests reduce product yield, grain size, storage time and quality, and also causes rapid spread of disease (Bisesi \& Koren 2003). For this reason, the use of pesticides for high yield and highquality food is an inevitable tool (De Schampheleire et al 2007; Matthews 2008). Although pesticides have important benefits for the development of agriculture, they also have many negative effects on people, animals and the environment (Belforte et al
2011). During the pesticide application, the required dose throughout the entire area must be properly applied to the target. Incomplete application causes negative effects such as weeds and harmful insects to be sustained by decreasing pesticide efficiency. On the other hand, excessive application leads to contamination of the soil and surface waters, and excessive pesticide residues. Since pesticides contain intense active ingredients, excessive pesticide residues on plants causes crop damage (Ozkan \& Reichhard 1993; Marck \& Luycx 1993). The quality of spraying is determined by characteristics such as mean diameters, uniformity of distribution, drop frequency and the coating ratio of the droplets 
collecting on the target surfaces. It is desirable that the amount of pesticide drift to the off-target area must be as low as possible, as the accumulation rate and coating rate is high for each treatment (Ozkan 1995; Gil \& Badiola 2007).

For high quality spraying, it is necessary to keep the spraying height constantly at an appropriate value. Spraying at too high a level results in spray drift, while a low-level setting causes untreated slivers and excessively sprayed strips in areas underneath the nozzle. The total effect appears to be very poor accumulation and deterioration in uniform distribution (Yoshida \& Maybank 1971). For this reason, it is of utmost importance that the treatment height is kept at a reasonable value to provide treatment in one go, to reduce pesticide drift, to obtain a more uniform pesticide distribution, to avoid disruption of the spray pattern and to provide adequate coverage (Wang et al 1993; Womac et al 2001; Wen \& Kidd 2005; Qasem 2011).

In published literature, the distance between the nozzles and also the nozzle angle is taken into account. For wide-angle nozzles, a lower spray height is preferred. For example, for a nozzle spacing of $50 \mathrm{~cm}$, a spray height of $50 \mathrm{~cm}$ is recommended at a $110^{\circ}$ nozzle angle (Langenakens et al 1999; Wilson et al 2008). However, when the spray is being applied, the spray height is constantly changing due to fluctuations in the land structure, to hills, tyres and vertical vibrations. Thus, the quality of the spraying is adversely affected (Langenakens et al 1995; Ramon et al 1997; Langenakens et al 1999). Based on a study conducted by Langenakens et al (1995), the spray deposit can vary between $0 \%$ and $1000 \%$ for vertical boom vibrations. When passive and active suspension systems are used, the level of spraying quality is increased by reducing the vertical vibrations and height errors (Ramon et al 1997). Passive suspension systems are based on balance, central rotation and damping suspension systems and do not require any power source (Frost 1984; Klein \& Kruger 2011). On the other hand, active suspension systems use sensors and actuators to balance the boom arm. If a height deviation is detected by the sensor, the actuator adjusts the set point by moving the boom in a downward or upward direction (O’ Sullivan 1986; Klein \& Kruger 2011).
Many theoretical and experimental studies have been carried out on passive and active suspension system applications (Musillami et al 1982; Frost 1984; O'Sullivan 1986; Frost \& O'Sullivan 1986; Marchant \& Frost 1989; Kennes et al 1999; Deprez et al 2002; Deprez et al 2003; Anthonis et al 2005; Sun \& Miao 2011; Koc \& Keskin 2011; Pontelli \& Mucheroni 2012). These systems control the vertical height of all or parts of the boom arms carrying the spray nozzles, and they keep the boom parallel to the ground. In these studies, hydraulic cylinders were also used as actuators.

This study differs from previous studies because it uses a PMTLSM to control the vertical motion of the nozzle, and for the independent adjustment of the height of a single spray nozzle and ability to track differently sized plants on a row.

\section{Material and Methods}

The test bench used to perform laboratory tests is presented in Figure 1. The variable speed conveyor belt with different sizes of artificial plants is $410 \mathrm{~cm}$ long and $60 \mathrm{~cm}$ wide. The conveyor belt speed is measured by a wheel-type incremental encoder (Autonics ENC-1-1-V-5, South Korea). The data acquisition card (National Instrument NI DAQ 6211, USA) and the graphical programming language (National Instrument LabVIEW 2013, USA) were used to read the distance information from the sensor and to calculate the analog voltage information commands to be sent to the analogue inputs of the motor servo drive. Vertical movement of the nozzle is provided by the high-performance PMTLSM (LinMot P01-23x160H-HP-R20, Switzerland) and is given in Figure 2. In the PMTLSM, high-speed linear motion is produced by direct electromagnetic force, there are no mechanical parts such as a mechanical gear and a belt-pulley system. In addition, there is no need for an oil tank, pump, filter or liquid transmission pipes. In addition, the motor's tubular configuration provides benefits such as easy installation, accuracy, high repeatability, high thrust density, low weight / force ratio and quiet operation from the direct drive linear motion system (LinMot 2016). 

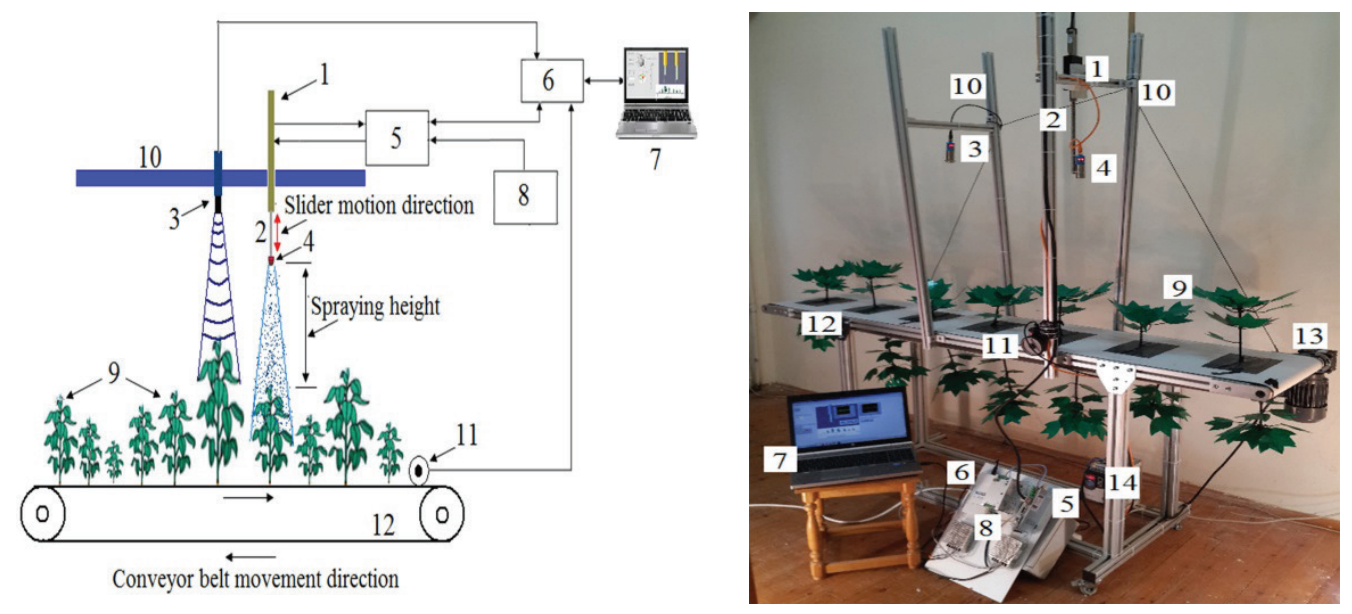

Figure 1- The laboratory test setup (schematic diagram in left, picture in right): 1, PMTLSM; 2, Slider; 3 , $1^{\text {st }}$ ultrasonic sensor; 4, $2^{\text {nd }}$ ultrasonic sensor; 5, servo driver; 6, DAQ board; 7, laptop; 8, power supply; 9, artificial plants; 10, bridge; 11 , wheel type encoder; 12 , conveyor belt; 13 , induction motor with reduction gear; 14, frequency converter

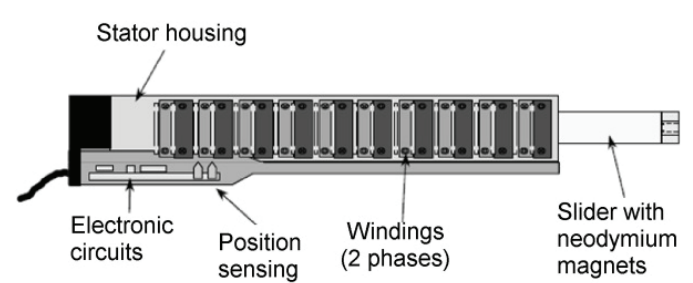

Figure 2- Assembly of PMTLSM

The servo drive (Linmot B1100 GP-HC, Switzerland) has a built-in, internal, proportional integral derivative (PID) controller that controls the linear travel position of the PMTLSM slider. The linear motor-defining parameters, PID controller gains, slider acceleration and maximum velocity information are entered manually into the driver via the servo drive software (LinMot Talk software version 6.0). The servo driver has maximum velocity and limited acceleration interpolation. In this interpolation process, the traditional PID controller output is damped to provide trapezoidal trajectory tracking according to the set acceleration and maximum velocity values (Figure 3 ). Thus, the slider travels from the current position to the target position at the maximum velocity with limited acceleration thereby avoiding unwanted position deviations. When the acceleration increases, the isosceles trapezoidal angles also increase, as seen in Figure 4. Thus, a motion profile is produced that will enable the target to be reached in a shorter time.

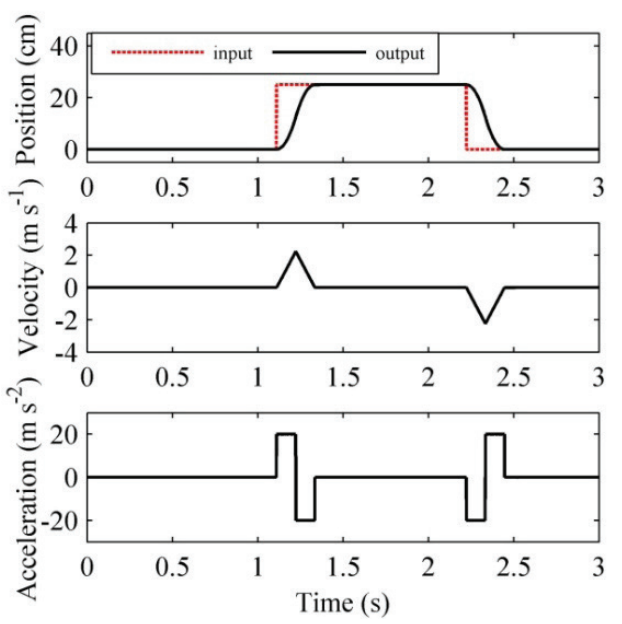

Figure 3- PMTLSM trapezoidal motion profile (for $25 \mathrm{~cm}$ position, $2.3 \mathrm{~m} \mathrm{~s}^{-1}$ velocity, $20 \mathrm{~m} \mathrm{~s}^{-2}$ acceleration) 
The first of the two ultrasonic distance sensors (Sick UM30 213113, Germany) in the system measures the profile of the plant while the second ultrasonic distance sensor measures the distance between the plant and the slider following the height control process. Tests were performed to determine the calibration characteristics of the ultrasonic sensor with an analog output voltage from 0 to $10 \mathrm{~V}$, a detection range from 20 to $130 \mathrm{~cm}$. The calibration characteristics obtained from distances measured using a fixed object is shown in Figure 5. The mathematical equation obtained by using the calibration characteristic of the ultrasonic distance sensor is given in Equation 1.

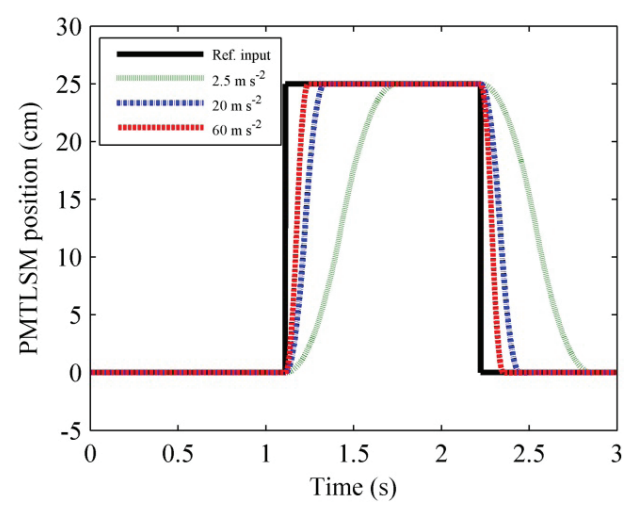

Figure 4- Trapezoidal motion profile for different acceleration values (Reference input, $0.45 \mathrm{~Hz}$ square wave signal)

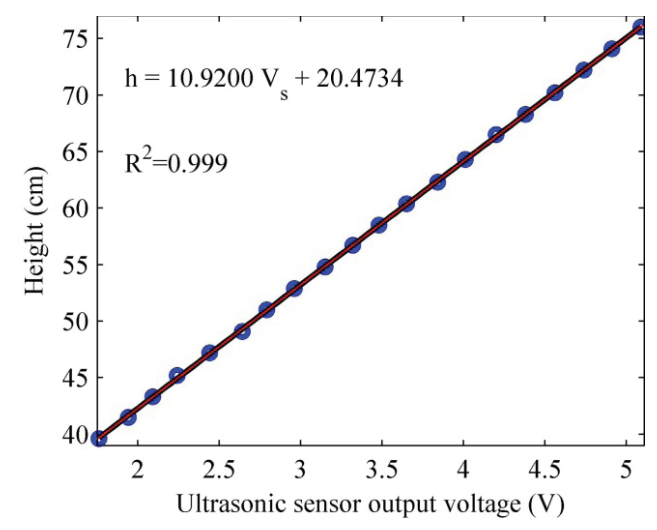

Figure 5-Calibration characteristic of the ultrasonic distance sensor

$$
h=10.9200 V_{s}+20.4734
$$

Where; $V_{s}$ is the voltage (in volts) read from the sensor, and $h$ is the height (in $\mathrm{cm}$ ). This equation is used to calculate the distance between the sensor and the object according to the voltage measured from the sensor output. For synthesis of the drive signal a test was performed using a measured height. The characteristic figure obtained according to the test result is given in Figure 6. Using this characteristic, Equation 2 was obtained.

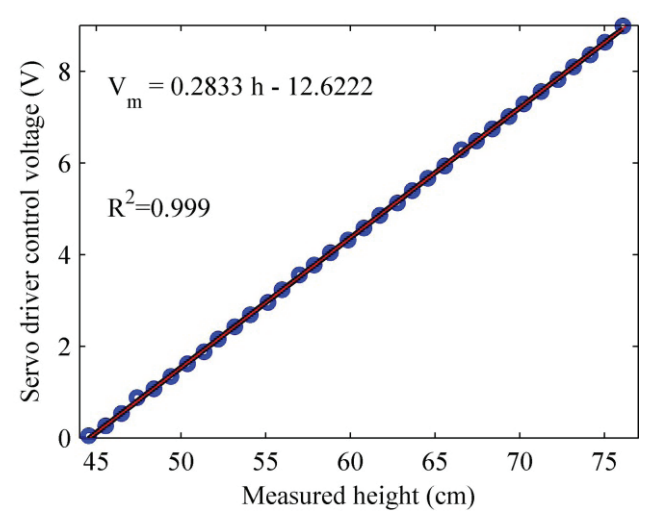

Figure 6- Servo driver analog control signal characteristic according to height

$V_{m}=0.2833 h+12.6222$

Where; $h$ is the height (in $\mathrm{cm}$ ) and $V_{m}$ is the control signal (in volts). This equation provides a calculation of the analog control signal to be applied to the servo drive inputs to achieve the slider's 50 $\mathrm{cm}$ reference height using the distance information obtained from the sensor. Since the servo drive inputs are suitable for a 0 to $10 \mathrm{~V}$ analogue voltage, the control signal is limited between these values. In the PID position controller, the proportional gain, integral gain and derivative gain parameters significantly affect the performance of the control. These parameters are set $2.5 \mathrm{~A} \mathrm{~mm}^{-1}, 0 \mathrm{~A} \mathrm{~mm}^{-1} \mathrm{~s}^{-1}$ and $7.5 \mathrm{As} \mathrm{m}^{-1}$ respectively. Since there is an oscillation risk in the slider position at steady-state conditions, integral gain is set to the zero as recommended by the PMTLSM manufacturer. 
In the laboratory experiments, the conveyor belt was operated at speeds of $1,2,3,4 \mathrm{~km} \mathrm{~h}^{-1}$. At every speed, the PMTLSM acceleration was set manually via the servo drive software to be $2.5,5,10,20,40$, $60 \mathrm{~m} \mathrm{~s}^{-2}$, respectively.

The coefficient of variation (CV) and linear motor RMS current values (the root mean square values of motor current values calculated for each test) were used to test the performance of the system. CV is taken as the deviation from the average height. The RMS current is an important criterion in determining the amount of energy consumed and the amount of warm-up time for the electric motors. The linear motor RMS current values were calculated using the data received from the servo drive.

Analysis of variance (ANOVA) was used to investigate: 1 . Whether there is a difference between the $\mathrm{CV}$ averages, and 2. Whether there is a difference between the PMTLSM RMS current averages. When a significant difference occurred, the LSD multiple comparison test was used to identify which subgroups caused the differences.

After laboratory experiments, field experiments were carried out on land where real plants were found in different sizes. For the field test, the system developed in the laboratory was adapted to a tractor (Figure 7). In the field tests the driving speed was set at 4,8 and $12 \mathrm{~km} \mathrm{~h}^{-1}$ detected by a GPS device (Aselsan ASN3040, Turkey), because Langenakens et al (1995), indicated that the tractor speed changes between 3 and $12 \mathrm{~km} \mathrm{~h}^{-1}$ in spraying applications. The PMTLSM acceleration is set to $20 \mathrm{~m} \mathrm{~s}^{-2}$, which was found to be the best value in laboratory tests. The $2^{\text {nd }}$ ultrasonic sensor on the test setup was replaced with a conical type nozzle for spray tests on the field. A conventional type of hand pump knapsack sprayer (Basar Memeto, Turkey) was used as the sprayer at 4.9 bar of service pressure. Data for the wind speed, air temperature and average humidity during field experiments were recorded at $5.9 \mathrm{~m} \mathrm{~s}^{-1}, 23{ }^{\circ} \mathrm{C}$ and $41 \%$. Water-sensitive paper (WSP) cards $(26 \times 76$ $\mathrm{mm}$, Syngenta, Switzerland) are used to visualize, measure and map out the spray distribution and for analysis of the spray coverage area. Spray droplets leave a blue stain on the yellow surface of the WSP (Salyani et al 2013). In this study, spray distribution was charecterized by measuring spray coverage on the WSP. Evans et al (1994), found a strong correlation between the spray coverage obtained from image analysis and the mass deposits obtained by chemical analysis provided that the spray coverage is fairly uniform. Six WSP cards were located at approximately 30 to $65 \mathrm{~cm}$ directly under the nozzle and water was used as the spray liquid. In accordance with previous studies (Salyani et al 2013) only a sample area of $2 \times 2 \mathrm{~cm}$ was used at the center of the WSP cards for image analysis. WSP cards were analyzed using the Matlab image processing toolbox. The percentage of wetted area or spray coverage was calculated for the samples after the spray application. WSP card images were converted to binary values by converting the image to gray scale and then a threshold was applied to assign a value of 0 or 1 to pixels based on their intensity. Spray coverage area was calculated as the ratio of the number of pixels exposed to water, divided by the total number of pixels (Sama et al 2016).

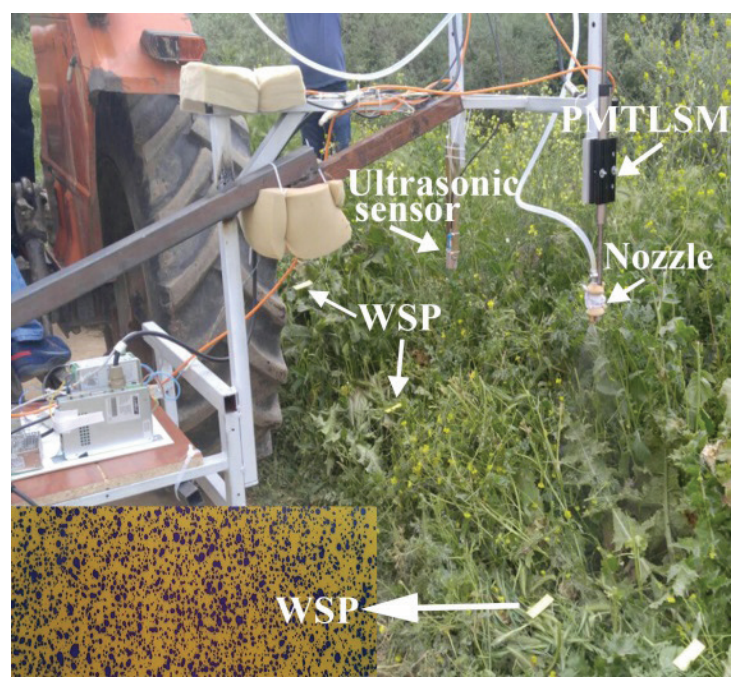

Figure 7- The field test setup 


\section{Results and Discussion}

\subsection{Laboratory tests results}

The CV value was calculated using the data in Figure 8 at $10.79 \%$ for the average height of 50 $\mathrm{cm}$ when control was not applied to the system. Some graphs related to the data obtained from the experiments are given in Figures 9 to 11 . It can be seen from the figures that the system tries to keep the nozzle at about the $50 \mathrm{~cm}$ set height for different accelerations and conveyor speed values. The tests were performed for three repetetions at 4 different conveyor belt speeds and 6 different PMTLSM accelerations. The results of the variance analysis for the data obtained in all experiments are shown in Table 1. This table indicates that the change in PMTLSM acceleration and conveyor speed, and the interaction between them, had a statistically significant effect $(\mathrm{P}<0.05)$ on the CV and PMTLSM RMS current. The statistical importance of interaction is that it indicates how the effect of increasing acceleration differs according to the changing conveyor speed values. According to the LSD test shown in Table 2 , the CV value decreased when acceleration was increased. This decrease was not statistically significant $(\mathrm{P}>0.05)$ between $20 \mathrm{~m} \mathrm{~s}^{-2}$ and 60 $\mathrm{m} \mathrm{s}^{-2}$. Variations of the $\mathrm{CV}$ values according to accelerations and conveyor belt speeds are shown in Figure 12. It is seen from the figures that the rate of decrease of $\mathrm{CV}$ varies according to the speed. The effect of acceleration is more visible at higher conveyor speeds. When the acceleration is increased from $20 \mathrm{~m} \mathrm{~s}^{-2}$ to $60 \mathrm{~m} \mathrm{~s}^{-2}$, the $\mathrm{CV}$ values decrease only for $4 \mathrm{~km} \mathrm{~h}^{-1}$ of speed, while others are changed little. It can be said that the increase in the amount of vibration generated in the motor causes a reduction in the acceleration effect after $20 \mathrm{~m} \mathrm{~s}^{-2}$. According to the conveyor belt speed, if the speed was further increased in value by over $2 \mathrm{~km} \mathrm{~h}^{-1}$, the increase in the $\mathrm{CV}$ value became statistically significant $(\mathrm{P}<0.05)$. It can be said that this is caused by the ultrasonic sensor which is negatively affected by the increasing conveyor speeds (Iida \& Bursk 2002; Zaman et al 2007;
Koc \& Keskin 2011). The effect of PMTLSM acceleration and conveyor speeds on the PMTLSM RMS currents are presented in Table 1, Table 2 and Figure 13. The results of Table 1 indicate that the change of PMTLSM acceleration and conveyor speed, and the interaction between them, affect the PMTLSM RMS current $(\mathrm{P}<0.05)$. From the results of Table 2 it was found that the effect of conveyor speed was found to be statistically significant $(\mathrm{P}<0.05)$ for acceleration values greater than $10 \mathrm{~m} \mathrm{~s}^{-2}$. The PMTLSM RMS current increases as the acceleration increases. The increase in the RMS current was found to be significant $(\mathrm{P}<0.05)$ when the acceleration was increased from $5 \mathrm{~m} \mathrm{~s}^{-2}$ to $60 \mathrm{~m} \mathrm{~s}^{-2}$. This is due to the fact that PMTLSM tries to respond very quickly to the measured height, which changes very rapidly. RMS current increases when the conveyor speed increases, When the speed increases from $2 \mathrm{~km} \mathrm{~h}^{-1}$ to $3 \mathrm{~km} \mathrm{~h}^{-1}$, the increase in the RMS current is not statistically significant $(\mathrm{P}>0.05)$. A current value of 2.48 in Figure 13 represents the maximum allowed RMS current for the PMTLSM. It can be seen from the figure that the PMTLSM RMS current increases at the $40 \mathrm{~m}$ $\mathrm{s}^{-2}$ and $60 \mathrm{~m} \mathrm{~s}^{-2}$ acceleration values as the belt speed increases, but there is no increase for smaller acceleration values. The maximum allowed instantaneous current value of the motor used in this study is $11 \mathrm{~A}$, but the maximum continuous current is $2.48 \mathrm{~A}$. Because the warming of the motor windings (caused by losses in the copper) is proportional to the square of the current (Wang et al 2012), the increase in the RMS current after the limit value causes the motor windings to overheat and damage the winding insulation and demagnetize the permanent magnets in the slider. For this reason, the RMS current has a limiting factor as the motor acceleration value increases. This means that the acceleration value must be kept less than $60 \mathrm{~m} \mathrm{~s}^{-2}$ in the system. According to statistical analysis results obtained, the PMTLSM acceleration and conveyor belt speed were found to be important variables affecting the $\mathrm{CV}$ and the RMS current values. 


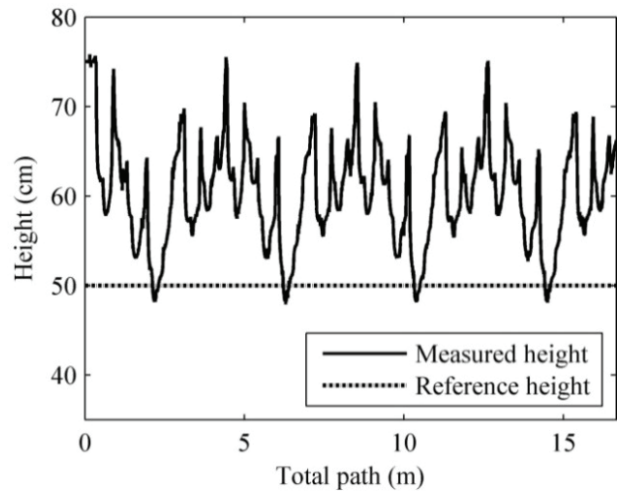

Figure 8- The measured height between by $2^{\text {nd }}$ ultrasonic sensor and artificial plants along the total path (artificial plant profile)

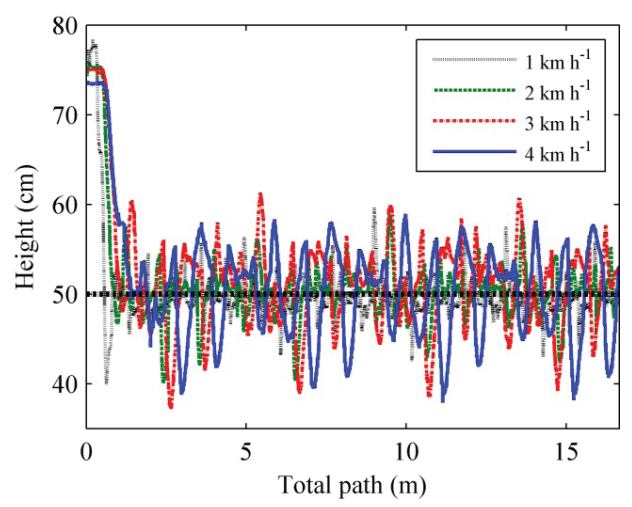

Figure 9- The height measured by $2^{\text {nd }}$ ultrasonic sensor at all speeds for acceleration of $2.5 \mathrm{~m} \mathrm{~s}^{-2}$

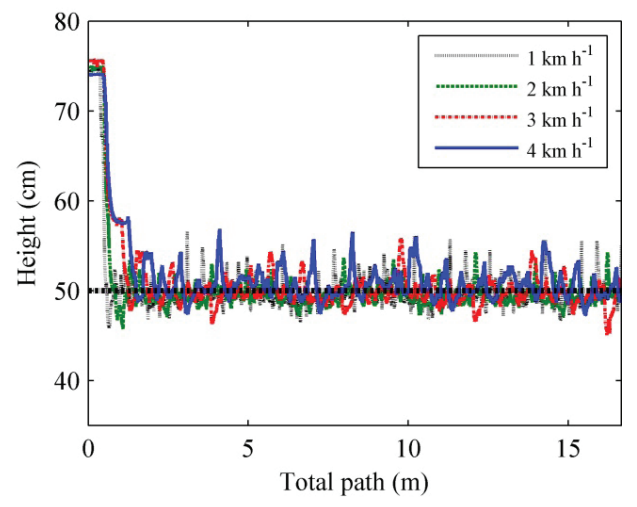

Figure 10- The height measured by $2^{\text {nd }}$ ultrasonic sensor at all speeds for acceleration of $20 \mathrm{~m} \mathrm{~s}^{-2}$

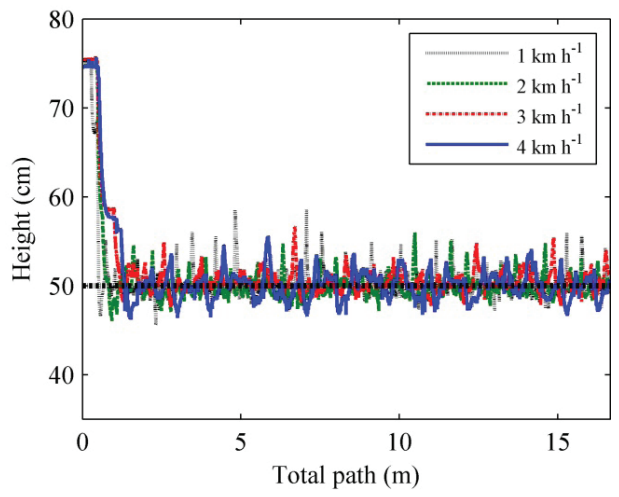

Figure 11- The height measured by $2^{\text {nd }}$ ultrasonic sensor at all speeds for acceleration of $60 \mathrm{~m} \mathrm{~s}^{-2}$

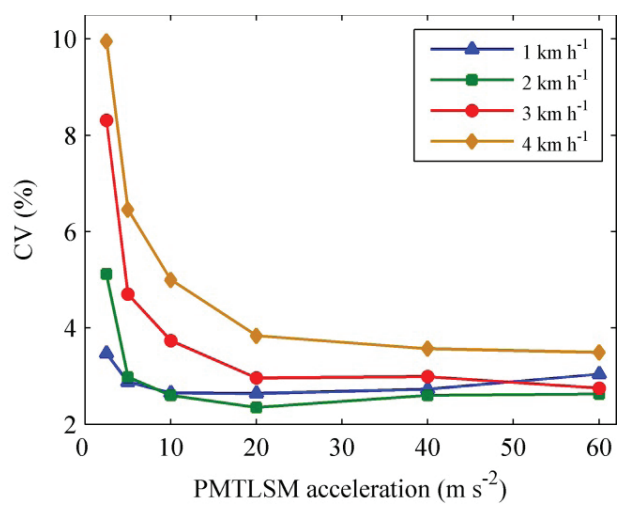

Figure 12- The relationship between PMTLSM acceleration and $\mathrm{CV}$ for different conveyor speed

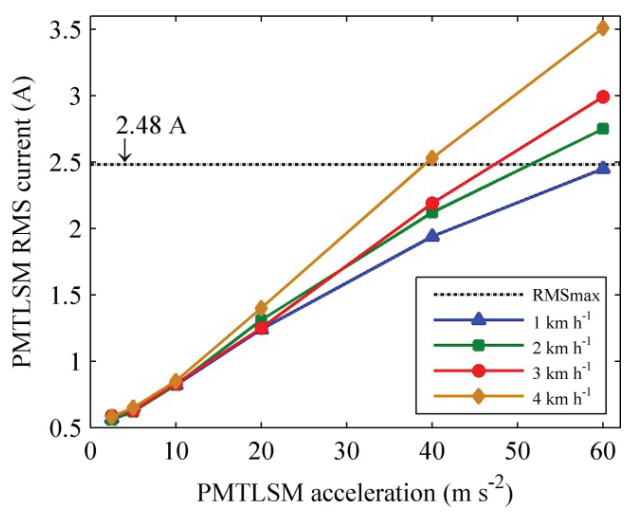

Figure 13- The relationship between PMTLSM acceleration and PMTLSM RMS current for different conveyor speed 
Table 1- The results of variance analysis of the mean values of the CV and PMTLSM RMS current

\begin{tabular}{lcrrrr}
\hline \multirow{2}{*}{$\begin{array}{l}\text { Source of } \\
\text { variation }\end{array}$} & \multicolumn{2}{c}{$C V$} & \multicolumn{3}{c}{ PMTLSM RMS current } \\
\cline { 2 - 6 } & $\begin{array}{c}\text { Degree of } \\
\text { freedom }\end{array}$ & $\begin{array}{c}\text { Sum of } \\
\text { squares }\end{array}$ & Fratio & $\begin{array}{c}\text { Sum of } \\
\text { squares }\end{array}$ & F ratio \\
\hline Acceleration (A) & 5 & 0.983 & $95.96^{*}$ & 54.64 & $1691.60^{*}$ \\
Speed (S) & 3 & 0.687 & $111.72^{*}$ & 0.91 & $47.08^{*}$ \\
$\mathrm{~A} \times \mathrm{S}$ & 15 & 0.247 & $8.04^{*}$ & 1.49 & $15.36^{*}$ \\
Error & 48 & 0.098 & & 0.31 & \\
Total & 71 & 2.015 & & 57.35 & \\
\hline
\end{tabular}

*, significant at $\mathrm{P}<0.05$

Table 2- Mean values and significance groups of CV and PMTLSM RMS current

\begin{tabular}{|c|c|c|c|c|c|c|c|c|c|c|}
\hline \multirow{2}{*}{ Acceleration } & \multicolumn{4}{|c|}{$C V(\%)$} & \multicolumn{6}{|c|}{ PMTLSM RMS current (A) } \\
\hline & $1 \mathrm{~km} \mathrm{~h}^{-1}$ & $2 \mathrm{~km} \mathrm{~h}^{-1}$ & $3 \mathrm{~km} \mathrm{~h}^{-1}$ & $4 \mathrm{~km} \mathrm{~h}^{-1}$ & Mean & $1 \mathrm{~km} \mathrm{~h}^{-1}$ & $2 \mathrm{~km} \mathrm{~h}^{-1}$ & $3 \mathrm{~km} \mathrm{~h}^{-1}$ & $4 \mathrm{~km} \mathrm{~h}^{-1}$ & Mean \\
\hline $2.5 \mathrm{~m} \mathrm{~s}^{-2}$ & $0.54^{\mathrm{efg}}$ & $0.71^{\mathrm{d}}$ & $0.92^{\mathrm{b}}$ & $1.00^{\mathrm{a}}$ & $0.79^{\mathrm{A}}$ & $0.57^{j}$ & $0.56^{\mathrm{j}}$ & $0.59^{j}$ & $0.58^{\mathrm{j}}$ & $0.58^{\mathrm{E}}$ \\
\hline $5.0 \mathrm{~m} \mathrm{~s}^{-2}$ & $0.46^{\mathrm{h}}$ & $0.47^{\mathrm{gh}}$ & $0.67^{d}$ & $0.81^{\mathrm{c}}$ & $0.60^{\mathrm{B}}$ & $0.65^{j}$ & $0.62^{j}$ & $0.63^{j}$ & $0.65^{\mathrm{j}}$ & $0.64^{\mathrm{E}}$ \\
\hline $10 \mathrm{~m} \mathrm{~s}^{-2}$ & $0.42^{\mathrm{hi}}$ & $0.41^{\mathrm{hi}}$ & $0.57^{\mathrm{e}}$ & $0.70^{\mathrm{d}}$ & $0.52^{\mathrm{C}}$ & $0.82^{\mathrm{i}}$ & $0.82^{\mathrm{i}}$ & $0.83^{\mathrm{i}}$ & $0.85^{\mathrm{i}}$ & $0.83^{\mathrm{D}}$ \\
\hline $20 \mathrm{~m} \mathrm{~s}^{-2}$ & $0.42^{\mathrm{hi}}$ & $0.37^{\mathrm{i}}$ & $0.47^{\mathrm{gh}}$ & $0.58^{\mathrm{e}}$ & $0.46^{\mathrm{D}}$ & $1.24^{\mathrm{h}}$ & $1.31^{\mathrm{gh}}$ & $1.25^{\mathrm{h}}$ & $1.40^{\mathrm{g}}$ & $1.30^{\mathrm{C}}$ \\
\hline $40 \mathrm{~m} \mathrm{~s}^{-2}$ & $0.44^{\mathrm{hi}}$ & $0.41^{\mathrm{hi}}$ & $0.47^{\mathrm{gh}}$ & $0.55^{\mathrm{ef}}$ & $0.47^{\mathrm{D}}$ & $1.94^{\mathrm{f}}$ & $2.12^{\mathrm{e}}$ & $2.19^{\mathrm{e}}$ & $2.53^{\mathrm{d}}$ & $2.20^{\mathrm{B}}$ \\
\hline $60 \mathrm{~m} \mathrm{~s}^{-2}$ & $0.48^{\mathrm{fgh}}$ & $0.42^{\mathrm{hi}}$ & $0.44^{\mathrm{hi}}$ & $0.54^{\mathrm{efg}}$ & $0.47^{\mathrm{D}}$ & $2.45^{\mathrm{d}}$ & $2.75^{\mathrm{c}}$ & $2.99^{\mathrm{b}}$ & $3.51^{\mathrm{a}}$ & $2.92^{\mathrm{A}}$ \\
\hline Mean & $0.46^{\mathrm{C}}$ & $0.47^{\mathrm{C}}$ & $0.59^{\mathrm{B}}$ & $0.70^{\mathrm{A}}$ & & $1.28^{\mathrm{C}}$ & $1.36^{\mathrm{B}}$ & $1.41^{\mathrm{B}}$ & $1.59^{\mathrm{A}}$ & \\
\hline $\mathrm{LSD}_{0.05}$ & \multicolumn{5}{|c|}{ A: $0.037 \mathrm{~S}: 0.030 \mathrm{AxS}: 0.074$} & \multicolumn{5}{|c|}{ A: $0.066 \mathrm{~S}: 0.054 \mathrm{AxS}: 0.132$} \\
\hline
\end{tabular}

$A$, PMTLSM acceleration; $S$, Conveyor belt speed; uppercase letters represent groups of A and $\mathrm{S}$ means, lowercase letters represent groups of $\mathrm{A} \times \mathrm{S}$ interaction means; $(\mathrm{P}<0.05)$

The average height values for each trial in laboratory experiments were found to be between a minimum of $49.47 \mathrm{~cm}$ and a maximum of $51.05 \mathrm{~cm}$, as shown in Table 3. It can be seen from the table that the nozzle-height control system developed in this study was able to keep the nozzle within a very close mean of the set point of $50 \mathrm{~cm}$ in height.

Table 3- The average height values for each trial in laboratory experiments

\begin{tabular}{lllll}
\hline \multirow{2}{*}{ Acceleration } & \multicolumn{4}{c}{ Mean height $(\mathrm{cm})$} \\
\cline { 2 - 5 } & $1 \mathrm{~km} \mathrm{~h}^{-1}$ & $2 \mathrm{~km} \mathrm{~h}^{-1}$ & $3 \mathrm{~km} \mathrm{~h}$ & $4 \mathrm{~km} \mathrm{~h}^{-1}$ \\
\hline $2.5 \mathrm{~m} \mathrm{~s}^{-2}$ & 50.54 & 50.01 & 50.03 & 49.99 \\
$5.0 \mathrm{~m} \mathrm{~s}^{-2}$ & 50.12 & 50.01 & 49.64 & 49.47 \\
$10 \mathrm{~m} \mathrm{~s}^{-2}$ & 49.51 & 50.03 & 50.68 & 51.05 \\
$20 \mathrm{~m} \mathrm{~s}^{-2}$ & 50.12 & 50.09 & 50.88 & 50.95 \\
$40 \mathrm{~m} \mathrm{~s}^{-2}$ & 50.14 & 49.70 & 50.64 & 50.27 \\
$60 \mathrm{~m} \mathrm{~s}^{-2}$ & 50.05 & 48.82 & 50.98 & 50.22 \\
\hline
\end{tabular}

\subsection{Field tests results}

The average height and CV values obtained from experiments are shown in Table 4. CV value of $16.77 \%$ were obtained while the nozzle was stationary (without nozzle height control). However, when height control is applied, this $\mathrm{CV}$ value decreases to $5.17 \%, 4.98 \%, 4.09 \%$ respectively for driving speeds of 12,8 and $4 \mathrm{~km} \mathrm{~h}^{-1}$. The reason for the increase in $\mathrm{CV}$ value with the increase in speed can be explained as follows; The increase in the driving speed reduces the measurement accuracy of the ultrasonic sensor (Iida \& Bursk 2002; Zaman et al 2007; Koc \& Keskin 2011), causing the test platform vibration to increase (Langenakens et al 1999; Pontelli \& Mucheroni 2012). WSP card samples obtained from field trials for three driving speed are shown in Table 5, where the number under each sample represents the percentage of the 
Table 4- Mean and CV values of nozzle height for different driving speeds in the field tests

\begin{tabular}{lcrr}
\hline Control situation & $\begin{array}{c}\text { Driving speed } \\
\left(\mathrm{km} \mathrm{h}^{-1}\right)\end{array}$ & $\begin{array}{r}\text { Mean } \\
(\mathrm{cm})\end{array}$ & $\begin{array}{r}\mathrm{CV} \\
(\%)\end{array}$ \\
\hline \multirow{3}{*}{ With height control } & 4 & 49.77 & 4.09 \\
& 8 & 49.94 & 4.98 \\
Without height control & 12 & 50.70 & 5.17 \\
\hline
\end{tabular}

wetted area. The mean of wetted area percentage (WA) and Uniformity of Distribution (UD) were calculated over the six samples for each speed (Table 5). The information in Table 5 reveals that the percentage of wetted area or spray coverage is different in the forward direction when the height control is not applied. At the lowest nozzle height of $30 \mathrm{~cm}$, it could be clearly seen that for all speeds,

Table 5- Mean of wetted area and uniformity of distribution for different driving speeds in the field tests

\begin{tabular}{|c|c|c|c|c|c|c|c|}
\hline Speed & \multicolumn{7}{|c|}{ Sample number (Nozzle height) } \\
\hline $\mathrm{km} \mathrm{h}^{-1} 1(30 \mathrm{~cm})$ & $2(40 \mathrm{~cm})$ & $3(50 \mathrm{~cm})$ & $4(55 \mathrm{~cm})$ & $5(60 \mathrm{~cm})$ & $6(65 \mathrm{~cm})$ & WA $(\%)$ & $U D(\%)$ \\
\hline \multicolumn{8}{|c|}{ Nozzle-height control not applied } \\
\hline 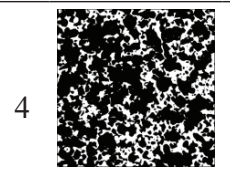 & W & 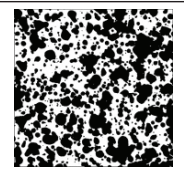 & 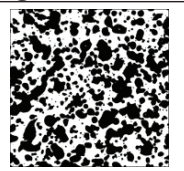 & ons & 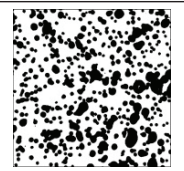 & 50.43 & 74.83 \\
\hline 70.54 & 54.30 & 53.37 & 50.69 & 38.90 & 34.79 & & \\
\hline 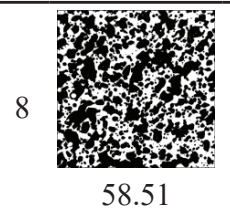 & $y_{x+3}$ & $\begin{array}{l}6 \\
6 \% 6 \\
6 x\end{array}$ & की & $\begin{array}{l}3+4 \\
4+4\end{array}$ & 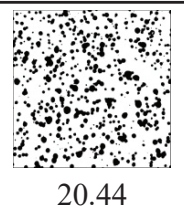 & 33.79 & 58.21 \\
\hline 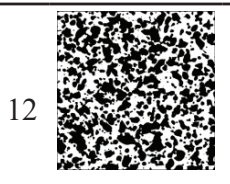 & \% & $\begin{array}{l}3 \\
3\end{array}$ & $\begin{array}{l}4+, \\
4,4\end{array}$ & 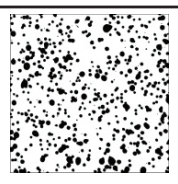 & कान & 28.5 & 56.57 \\
\hline 51.34 & 31.85 & 26.82 & 25.03 & 19.46 & 16.73 & & \\
\hline \multicolumn{8}{|c|}{ Nozzle-height control applied } \\
\hline 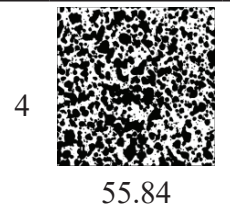 & 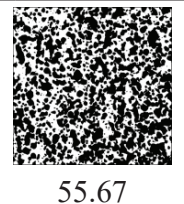 & Whom & ond & 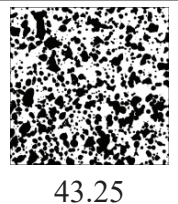 & कom & 49.59 & 88.06 \\
\hline 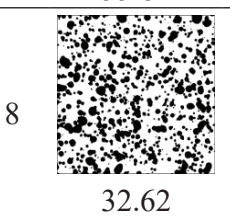 & 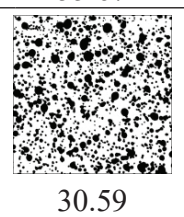 & 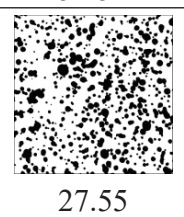 & 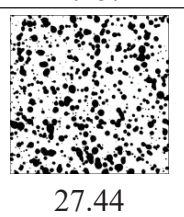 & $\begin{array}{l}6+2 \\
6+2 \\
6+2\end{array}$ & 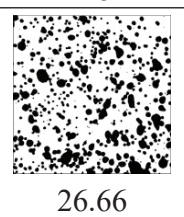 & 28.56 & 91.33 \\
\hline 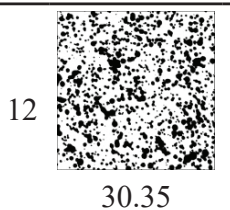 & 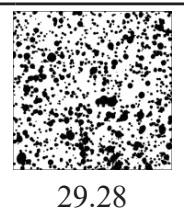 & 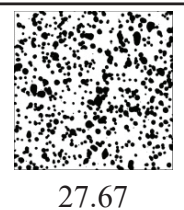 & 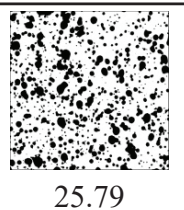 & $\begin{array}{c}\text { की } \\
\text { का } \\
\text { की } \\
23.71\end{array}$ & 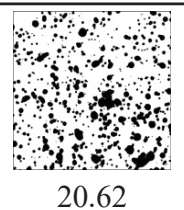 & 26.23 & 86.11 \\
\hline
\end{tabular}


the wetted area percentage was the largest on the sample card for sample number 1, while for the highest nozzle height of $65 \mathrm{~cm}$ the wetted area percentage was the least on sample number 6 . It is indicated in the study of (Al-Gaadi 2010) that when the distance between the nozzle and the target was small, the highest volume and application rate was found over a narrow area directly under the nozzle. On the other hand, when the height between the target and the nozzle increases, the spray volume and application rate was decreased directly under the nozzle and a larger area was sprayed. Yoshida \& Maybank (1971) emphasized that for shorter distances in droplet movement towards the target, larger droplets at higher speeds can hit the target, and droplet bouncing and fragmentation can occur. This situation may negatively affect the distribution uniformity and the accumulation amount on the target. It may be said that when the distance between the nozzle and the target is large, spraydrift-which means that the sprayed droplets goes out of the target area-is a reason for the wetted area percentage to be small. Balsari et al (2017), pointed out that spray-drift increased significantly when the spraying height was increased from $30 \mathrm{~cm}$ to $50 \mathrm{~cm}$, and from $50 \mathrm{~cm}$ to $70 \mathrm{~cm}$, and the effect of boom height is independent of the nozzle type. Lardoux et al (2007), indicated that the dose obtained in $\mathrm{L}$ ha ${ }^{-1}$ decreases when the height increases. Losses depend on evaporation, drifting and dispersal of droplets. It is shown from Table 5 that, when speed increased, the WA value decreased for all trials. The biggest WA value was obtained at $4 \mathrm{~km} \mathrm{~h}^{-1}$ and the smallest was obtained at $12 \mathrm{~km} \mathrm{~h}^{-1}$. Wolf et al (1997), reported that increased speed decreased the spray deposit under the nozzle center. Ooms et al (2003), found that there is a strong correlation between horizontal motion and longitudinal spray coverage in the laboratory and under field conditions, and they indicated that spray coverage is inversely proportional to the horizontal speed. They also stated that the speed increase tends to increase the risk of spray-drift. Results from field measurements reported by Miller \& Smith (1997), indicated that spray-drift increased aproximately $51 \%$ when speed was increased from 4 to $8 \mathrm{kmh}^{-1}$. Langenakens et al (1995), emphasized that at a speed greater than $4 \mathrm{~km} \mathrm{~h}^{-1}$ the amount of the chemical has to be increased to achieve the desired effect. As it can be seen from Table 5, when the proposed nozzle-height control was applied, the Uniformity of Distribution (UD) values were increased in the forward direction according to the fixed nozzle-height condition from $74.83 \%$ to $88.06 \%$ for $4 \mathrm{~km} \mathrm{~h}^{-1}$ speed, from $58.21 \%$ to $91.33 \%$ for $8 \mathrm{~km} \mathrm{~h}^{-1}$ and from $56.57 \%$ to $86.11 \%$ for $12 \mathrm{~km} \mathrm{~h}^{-1}$. From this, it can be concluded that as the nozzle height control is applied, system produces better spray distribution in the forward direction.

\section{Conclusions}

In this study, a spray nozzle-height control system developed using a PMTLSM was tested in the laboratory environment and under field conditions. According to the results obtained, it can be said that the developed height control system is affected by the PMTLSM acceleration and speed. For this system, the optimal acceleration value was found to be $20 \mathrm{~m} \mathrm{~s}^{-2}$, according to the data obtained from laboratory experiments. Both the laboratory tests and field tests showed that the CV value was reduced when the nozzle height control was applied. In the field tests when the height control is applied, the uniformity of distribution increased significantly in the forward direction. According to the results, if this system is mounted on a conventional pesticide sprayer, excessive and incomplete spraying of the pesticides will be reduced when applied in the field.

\section{Acknowledgements}

This study was supported by Dumlupinar University Scientific Research Projects Unit. (Projects number, 2013-25).

\section{References}

Al-Gaadi K A (2010). Effect of nozzle height and type on spray density and distribution for a ground field sprayer. Journal of the Saudi Society of Agricultural Sciences 9(1): 1-12

Anthonis J, Audenaert J \& Ramon H (2005). Design optimisation for the vertical suspension of a crop 
sprayer boom. Biosystems Engineering 90(2): 153160

Balsari P, Gil E, Marucco P, Van de Zande J C, Nuyttens D, Herbst A \& Gallart M (2017). Field-crop-sprayer potential drift measured using test bench: effects of boom height and nozzle type. Biosystems Engineering 154: $3-13$

Belforte G, Eula G \& Raparelli T A(2011). New technique for safe pesticide spraying in greenhouses. In: M Stoytcheva (Eds), Pesticides-Formulations, Effects, Fate, InTech, Rijeka, Croatia, pp. 129-154

Bisesi M \& Koren H (2003). Handbook of Environmental Health: Biological, Chemical, and Physical Agents of Environmentally Related Disease. CRC press Boca Raton, New York

De Schampheleire M, Spanoghe P, Brusselman E \& Sonck S (2007). Risk assessment of pesticide spray drift damage in Belgium. Crop Protection 26(4): 602611

Deprez K, Anthonis J, Ramon H \& Van Brussel H (2002). Development of a slow active suspension for stabilizing the roll of spray booms-part 1: hybrid modelling. Biosystems Engineering 81(2): 185-191

Deprez K, Anthonis J \& Ramon H (2003). System for vertical boom corrections on hilly fields. Journal of Sound and Vibration 266(3): 613-624

Evans M D, Law S E \& Cooper S C (1994). Fluorescence spray deposit measurement via light intensified machine vision. Applied Engineering in Agriculture 10(3): 441-447

Frost A R (1984). Simulation of an active spray boom suspension. Journal of Agricultural Engineering Research 30: 313-325

Frost A R \& O'Sullivan J A (1986). Verification of a mathematical model for a passive spray boom suspension. Journal of Agricultural Engineering Research 34(3): 245-255

Gil E \& Badiola J (2007). Design and verification of a portable vertical patternator for vineyard sprayer calibration. American Society of Agricultural and Biological Engineers 23(1): 35-42

Iida M \& Bursk T F (2002). Ultrasonic sensor development for automatic steering control of orchard tractor. In: Proceeding Of The Conference Automation Tecnology For Off-Road Equipment, 26-27 July, Chicago, Illinois, USA, pp. 221-229
Kennes P, Ramon H \& Baerdemaeker J D (1999). Modelling the effect of passive vertical suspensions on the dynamic behavior of sprayer booms. Journal of Agricultural Engineering Research 72(3): 217-229

Klein R N \& Kruger G R (2011). Spray boom set-up on field sprayers. Extension Puplications g2091. Institute of Agriculture and Natural Resources, University of Nebraska Lincoln, USA

Koc C \& Keskin R (2011). Developing of PIC controlled active boom suspension systems for field sprayers. Journal of Agricultural Sciences 17(1): 24-33

Langenakens J J, Ramon H \& De Baerdemaeker J D (1995). A model for measuring the effect of tire pressure and driving speed on the horizontal sprayer boom movements and spray patterns. Transactions of the ASAE 38(1): $65-72$

Langenakens J J, Clijmans L, Ramon H \& Baerdemaeker J D (1999). The effects of vertical sprayer boom movements on the uniformity of spray distribution. Journal of Agricultural Engineering Research 74(3): 281-291

Lardoux Y, Sinfort C, Enfalt P \& Sevila F (2007). Test method for boom suspension influence on spray distribution, part I: Experimental study of pesticide application under a moving boom. Biosystems Engineering 96(1): 29-39

LinMot (2016). Linear motors introduction and overview.pdf, Edition 16, Sulzer Electronics, Zürich, Switzerland, http://www.linmot.com (Retrieve November 2016)

Marchant J A \& Frost A R (1989). Simulation of the performance of state feedback controllers for an active spray boom suspension. Journal of Agricultural Engineering Research 43(2): 89-101

Marck P \& Luycx A (1993). Het imago van de europese landbouw bij de publieke opinie. Leuven Acco, Leuven, Belgium

Matthews G A (2008). Pesticide Application Methods. Blackwell Science, Oxford, UK

Miller, P C H \& Smith R W (1997). The effect of forward speed on the drift from boom sprayers. In: Proceedings of the Brighton Crop Protection Conference-Weeds, 17-20 November, BCPC, Farnham, UK, pp. 399-407

Musillami S, Goffre P \& Sevilla F (1982). Les traitements par pulvérisation et les pulvérisateurs en agriculture. Toine 2. Études Du Cemagref. Antony, France, pp. $59-64$ 
Ooms D, Ruter R, Lebeau F \& Destain M F (2003). Impact of the horizontal movements of a sprayer boom on the longitudinal spray distribution in field conditions. Crop Protection 22: 813-820

O'Sullivan J A (1986). Simulation of the behaviour of a spray boom with an active and passive pendulum suspension. Journal of Agricultural Engineering Research 35(3): 157-173

Ozkan H E (1995). Herbicide Formulations, Adjuvants and Spray Drift Management. In: A E Smith (Eds), Hand On Weed Management Systems, Marcel Dekker, New York, pp. 217-244

Ozkan H E \& Reichard D L (1993). Effect of orifice wear on flow rate, spray pattern and droplet size distributions of fan-pattern nozzles. In: Proceedings of the $2^{\text {th }}$ International Symposium on Pesticides Application Techniques, 22-24 September, Strasbourg, France, pp. 159-166

Pontelli C O \& Mucheroni M F (2012). Co-simulation procedure for PID and fuzzy logic active controls strategies applied to a sprayers boom suspension. In: S Chakravarty (Eds), Technology and Engineering Applications of Simulink, InTech, Rijeka, Croatia, pp. 69-96

Qasem J R (2011). Herbicides Applications: Problems And Considerations. In: A Kortekamp (Eds), Herbicides and Environment, InTech, Croatia, pp. 643-664

Ramon H, Missotten B \& Baerdemaeker J D (1997). Spray boom motions and spray distribution: part 2, experimental validation of the mathematical relation and simulation results. Journal of Agricultural Engineering Research 66(1): 31-39

Salyani M, Zhu H, Sweeb R D \& Pai N (2013). Assessment of spray distribution with water-sensitive paper. Agricultural Engineering International: CIGR Journal 15(2): 101-111

Sama M P, Evans J T, Turer A P \& Dasika S S (2016). As-applied estimation of volumetric flow rate from a single sprayer nozzle series using water-sensitive spray cards. Transactions of the ASABE 59(3): 861869

Sun J \& Miao Y (2011). Modeling and simulation of the agricultural sprayer boom leveling system: Measuring Technology and Mechatronics Automation, IEEE Conference, 6-7 January, Shanghai, pp. 613-618

Wang L, Zhang N, Slocombe J W \& Kuhlman D K (1993). Measurement of spray distribution uniformity for agricultural nozzles using spectral analysis. In: $\mathrm{P}$ D Berger, B N Devisetty \& F R Hall (Eds), Pesticide Formulation and application systems, American Society for Testing and Materials, Philadelphia, pp. 265-279

Wang L, Xiong C, Wu Y \& Gan Z (2012). Study on iron loss in two kinds of moving-magnet linear motors. In: Proceeding of the International Compressor Engineering Conference, 16-19 July, Purdue University, West Lafayette, USA, pp. 2235

Wen P \& Kidd J G (2005). Electronic height indicator for agricultural machines. Australian Journal of Electrical and Electronics Engineering 2(1): 13-19

Wilson J, Nowatzki J \& Hofman V (2008). Selecting driftreducing nozzles. south dakota cooperative extension service, FS 919, Rev. 6/08

Wolf T M, Liu S H, Caldwell B C \& Hsiao A I (1997). Calibration of greenhouse spray chambers: The importance of dynamic nozzle patternation. Weed Technology 11(3): 428-435

Womac A R, Etheridge R, Seibert A, Hogan D \& Ray S (2001). Sprayer speed and venturi-nozzle effects on broadcast application uniformity. Transactions of the ASAE 44(6): 1437-1444

Yoshida K \& Maybank J (1971). Effect of the dynamic stability of spray booms on the dispersion characteristics of a flat fan spray. The Journal of Canadian Agricultural Engineering 13(1): 23-28

Zaman Q U, Schumann A W \& Hostler H K (2007). Quantifying sources of error in ultrasonic measurements of citrus orchards. Applied Engineering in Agriculture 23(4): 449-453 